\title{
The Jallikattu Fiasco: Week Long Protest against the Ban Enforced and the Role Played by Print Media
}

\author{
Shantharaju $S^{*}$ and Vivian Peter ${ }^{\dagger}$
}

\begin{abstract}
As the fourth pillar of democratic governments, media has a significant influence in the formation of general conclusions among the masses. The bull has stomped its way into featured news story in Tamil Nadu several times in the last decade. From the time that people of Tamil Nadu prepared to celebrate Pongal in 2017, a large number of individuals from different urban communities of the state came together in open spaces, such as coastal areas and playgrounds, challenging a Supreme Court directive prohibiting the essentially provincial spectacle of Jallikattu. Convenient conclusions have frequently been drawn with regard to debilitating injuries and even deaths. The 'game' has never been directed by anyone with precise control. The present paper is an attempt to understand how a section of media, mostly newspapers, portrayed this sensitive issue. The review conducts a comparison between one English daily and one vernacular daily, both covering the Chennai locale in Tamil Nadu and attempts to examine the stand taken by print media in the projection of Jallikattu.
\end{abstract}

Keywords: Jallikattu, PETA, Ban, Animal Welfare, Media framing, Supreme Court

\footnotetext{
* Christ University, Bengaluru, India; shantha.raju@christuniversity.in

† Christ University, Bengaluru, India; vivian.peter@men.christuniversity.in
} 


\section{Introduction}

Jallikattu has become a controversial subject because of the conflict between maintaining cultural ethos and honouring the legal framework. Time and again this has been a public debate due to lack of resolution on this multifaceted issue. It has often resulted in repulsive protests and uproar. However, this time, the protest for jallikattu has escalated to the extent of equating the very notion of being Tamilian as one who upholds the game. Irrespective of one's personal choices, at least in the public sphere, every section of society appears to have agreed to be a supporter of jallikattu. Rather than having a healthy debate, the masses gathered at Marina beach in January 2017 put the law and order at stake increasing the possibility of an aggressive protest turning into a violent one. The period in which the jallikattu fiasco occurred was crucial to the state as there were much more significant concerns at the time. In the months preceding the jallikattu protests, the state had witnessed two important events in its history: one of the longest farmers' protests as the state was announced as draught hit and the hospitalization of Chief Minister J Jayalalitha who was on her deathbed. Unlike both these issues, the Marina Beach protest was an effort towards the cultural preservation of jallikattu. It is interesting to understand this phenomenon and to observe the role of print media in balancing journalistic ethics when caught between emotions of the masses and the responsibility to report truth.

\subsection{About Jallikattu}

Jallikattu could be described as a bull-restraining festival practiced in Tamil Nadu as part of Pongal festivities and celebrations (in between 14-17, January, of ever year). The etymological roots of the word 'Jallikattu' is derived from the Tamil words 'Jalli' and 'Kattu.' Jalli alludes to gold or silver coins. Kattu means 'tied.' Consolidated together they imply "coins tied to the bulls' horns", which is viewed as the prize for whoever restrains a bull on the run. The bull that wins is utilized to benefit many other cattle safeguarding the local breed. To an extent, it is similar to Spain's bull fights, a showing of the skills of men against the bull's brute force. There are variations in Jallikattu from region to region; either the bull is directly released into an open ground or the bull is tied with a $15 \mathrm{~m}$ 
(49 ft.) rope and the participants attempt to wrap their arms or hands around the hump of the bull and clutch it to win the honor, etc.

It is prestigious as a customary 'game'. Thought to have originated some 2000 years ago. It has also been referred to several times in Sangam literature (Gautier, 2001). One of the most established blood sports, Jallikattu is held in the towns of Tamil Nadu as a part of the town celebration. The 'game' is mired in controversy because the game regularly results in significant injuries and even death. It has turned into a stage for a show of courage. Though not as brutal as Spain's bull-fights, there is a lack of systematic organization and training in bullfighting in India. Amidst the protests to reinstate the essence of the Pongal celebration, Jallikattu was organized resulting in 3 deaths in January, 2017 (Indian Express, January 22, Madurai). Between 2008-14, at least 43 people were killed and around thousands succumbed to injuries according to Animal Welfare Board of India (AWBI)'s report (T.K Rohit, The Hindu, January. 14, 2014).

\subsection{The present Controversy and PETA}

The hazard the game poses to both men and animal is never lost on anyone. Consequently, whether Jallikattu must be practiced or not has been a point of rational discussion. The Animal Welfare Board of India recorded a case in the Supreme Court of India for the prohibition on Jallikattu on account of cruelty to animals and the risk it caused to human security. On 7 May 2014, the Supreme Court of India ordered the state to ban Jallikattu. On 8 January 2016, Ministry of Environment and Forests allowed the traditional game under certain conditions which was stayed by Supreme Court on 16 January 2016 after Animal Welfare Board of India and PETA filed a case. These developments took place during the month of January, which is normally a period of festivals including the festive day on which jallikattu is organized. This led to the aggravation of the masses. The protest received spontaneous and tremendous support from local organizers and attracted the attention and enthusiasm of a few media houses. Print media has explicitly respected the issue with open hands and has guaranteed appropriate coverage from 8-16 January, 2016. After a large number 
of people gathering and mass protests taking place, the Governor of Tamil Nadu announced an ordinance and the Tamil Nadu legislature passed a bill for the continuation of jallikattu in January 2017.

\section{Review of literature}

\subsection{Affective Intelligence and Political Judgment by}

Affective intelligence is a theory proposed by George E. Marcus, W. Russell Neuman, Michael Mackuen (2000) on how emotions and reason interact to produce thoughtful, attentive citizenry. When a citizen encounters a threatening actor or event on the political horizon, a process of new evaluation and political judgment is triggered. The meaning of affective intelligence is to affect, to be provocative and to draw the reader's attention. It is connected to emotions depending on the intensity of encounters in the real world. Affective intelligence is linked to happenings and experiences of the world around. So the judgment or the conscious decision of a reader or person depends on mental interactions. Every event or encounter proposes a certain amount of information to the brain. The psychological interactions begin processing this information, finally resulting in a rational choice.

The newspapers provide such encounters, issues thereby feeding the mind an enormous amount of information to process. The whole process helps a reader to take a political stance and react physically as a response.

According to Renita Coleman and H Denis Wu (2010), newspapers act as an effective tool of mass media while promoting agendasetting. Media also offers a reflective, opinionated and framed emotional element which influences the readers/audience cognitively. Their research on the 2004 US elections emphasizes the same. "Emotions enhance citizen's rationality. Emotions, particularly negative ones...shape their political views". Though their research is primarily on the coverage of TV news, the theory applies to media in general. People tend to react more quickly and emotionally to negative portrayal than the positive stories. And hence, Jallikattu's ban is seen as an injustice done to Tamil Nadu and its traditions. Between January 2014-17 two major events 
moved the masses: 1) Supreme Court's ban 2) Legislative approval(23 January 2017) and Central governments permission to hold jallikattu (8 January 2016), which was at cross purpose with the SC order. It escalated to the extent of 'Jallikattu' becoming synonymous with 'Tamilian'. "If you are a Tamilian, you ought to be the supporter of Jallikattu" was the standard slogan clamored in the Marina beach protest.

McCombs and Bell (1996) offer a more insightful reading on the coverage of newspapers and their influence on the public:

"Newspapers provide a host of clues about the salience of the topics in the daily news - lead story on page one, other front page display, large headlines...These cues repeated day after day effectively communicate the importance of each topic..."

From the repetition to the pictures used and the page it is placed on, everything communicates the importance of the news item to the reader. In a way, this made the news as something that is to be read compulsorily. A close analysis of multiple editions or multiple publications gives away the agenda or stance of the news organization on the subject reported. McCombs and Bell argue that "cognitions usually govern attitudes and behavior - what a person knows, thinks, and believes. Hence, the agenda-setting function of the mass media implies a potentially massive influence".

These arguments are similar to affective intelligence which interprets the same subject from a cognitive perspective. A person witnessing enormous footage of news or reading or hearing the news regarding an event, yields to the media's agenda.

According to McCombs and Shaw's (1979), Agenda-Setting and Mass Communication theory, Media has its methods of functioning and viewing the world around it. Though any press organisation is a group of individuals with different perspectives and understandings of the world, as a media house, a specific method of representation is evident. The truth is not just a fact. It is instead, a projected truth or a media portrayed truth. This duality of the media's projection reflects certain perceptions and attitudes of a culture which shapes the public opinion. The advocacy function of media houses need not be objective or subjective always. It depends on the interest and commitment of the media house. 


\subsection{Research questions}

The legislation and Governor's office of Tamil Nadu amended earlier policies to allow for the continuation of Jallikattu as a consequence of the statewide protests on until 20 January 2017. The media reported that more than 5 lakh people gathered at Chennai's Marina beach alone. Though one can't negate contribution of social media mass mobilization, it is mostly newspapers and broadcast media which provided enormous coverage to the issue at the time of the event. The objective of the study is to examine the print media's role in influencing and shaping public opinion and its impact on the decisions of other institutions.

Though there is a broader scope this paper could look into - various aspects ranging from media psychology to content manipulation and its influence, the researchers would like to focus on the following specific objectives:

The following are research questions of the study

- To understand the role and significance of newspapers in lifting the ban against Jallikattu

- To understand media psychology in addressing a culturally sensitive issue

- To investigate the impact of newspaper stories on the decision to protest during the Jallikattu celebrations, 2017.

\section{Methodology}

The researchers have used content analysis procedures to follow a more organized and systematic approach towards the research. This method uses coding and interpretation of textual and image material. The data obtained through this qualitative method is of a descriptive nature and is explained/interpreted by the same means. The text-image based analysis is the means of examination used on the articles that appeared in both the periodicals selected for this study. Two major newspapers that are highly circulated have been considered for the present study. A leading English Newspaper, The Hindu and a leading vernacular newspaper, Dinathanthi, are discussed. The period for the analysis is from 13th January to 20th January 2017 which corresponds to one week 
before the mass gathering in Marina beach, i.e., 20 January 2017. According to the Dravidian culture, 14 January marks the beginning of the Pongal festival and is a public holiday. Therefore, there were no papers published on 15 January as newspaper offices were closed to observe the public holiday. Hence, it is appropriate to say seven issues of the two papers were selected, in the one week from 13 January 2017 to 20 January 2017. News items appear mostly on the main sheets of Indian newspapers rather than supplements, which have a common theme, that vary each day throughout the week. Supplements contain more peripheral feature stories rather than hard news coverage and hence only main sheets are included in the research, excluding supplements.

Various parameters (units of analysis) were predetermined and codes created by the researcher, before carrying out content analysis. A total number of stories, pictures carried, placement of the story according to page preference, the nature of images, space given to these articles and photographs have been analyzed. The photos were categorized into - happening, epitome and people. The actual pictures of the actions were considered to be 'happening', images of individuals mostly published along with the opinion pieces including celebrities are viewed as 'people' and other types of pictures including the file photos, graphics are considered 'epitome'. The parameters mentioned above focused on aspects such as positioning, the styling of the story, whether the story carried a tone of negativity, positivity or neutral stance. Page prominence in the form of front page or inside story was also characterized.

\section{Data Analysis}

The researcher selected the national daily, The Hindu and Tamil daily, Dinathanthi for content analysis. The text and images were the crucial elements considered in the research. Various parameters were incorporated into the study as mentioned above. The analysis of the compiled data from the multiple articles that appeared in the two papers were summarized for the parameters of styling, positioning, placement, tone and visual elements. The researchers obtained several distinct patterns that were evidently visible leading to some interesting results and conclusions. These patterns 
were interpreted in the context of the theoretical framework explained in the review of literature to allow for an in-depth understanding of the objectives of this study. The graphs shown below depict the comparison between the two selected newspapers. The researchers categorized the text-based content analysis into three different forms of article writing, namely: Lead story, Editorials and Opinion story.

The majority of stories regarding the Jallikattu turmoil were lead stories and these were strategically placed as front page articles. If The Hindu carried two stories every day with a picture on the cover page, Dinathanthi carried more than three pictures and articles every day.

Table 1 No. of articles and pictures that appeared in The Hindu, Chennai edition

\begin{tabular}{ccc}
\hline Issue(13-20 January) & Stories & Pictures \\
\hline 1 & 2 & 3 \\
2 & 3 & 4 \\
3 & 3 & 5 \\
4 & 3 & 4 \\
5 & 2 & 3 \\
6 & 8 & 13 \\
7 & 12 & 23 \\
Total & 33 & 55 \\
\hline
\end{tabular}

Table 2 No. of articles and pictures that appeared in Dinathanthi, Chennai edition

\begin{tabular}{ccc}
\hline Issue(13-20 January) & Stories & Pictures \\
\hline 1 & 5 & 5 \\
2 & 13 & 15 \\
3 & 8 & 13 \\
4 & 7 & 13 \\
5 & 7 & 23 \\
6 & 34 & 42 \\
7 & 37 & 54 \\
Total & 111 & 165 \\
\hline
\end{tabular}



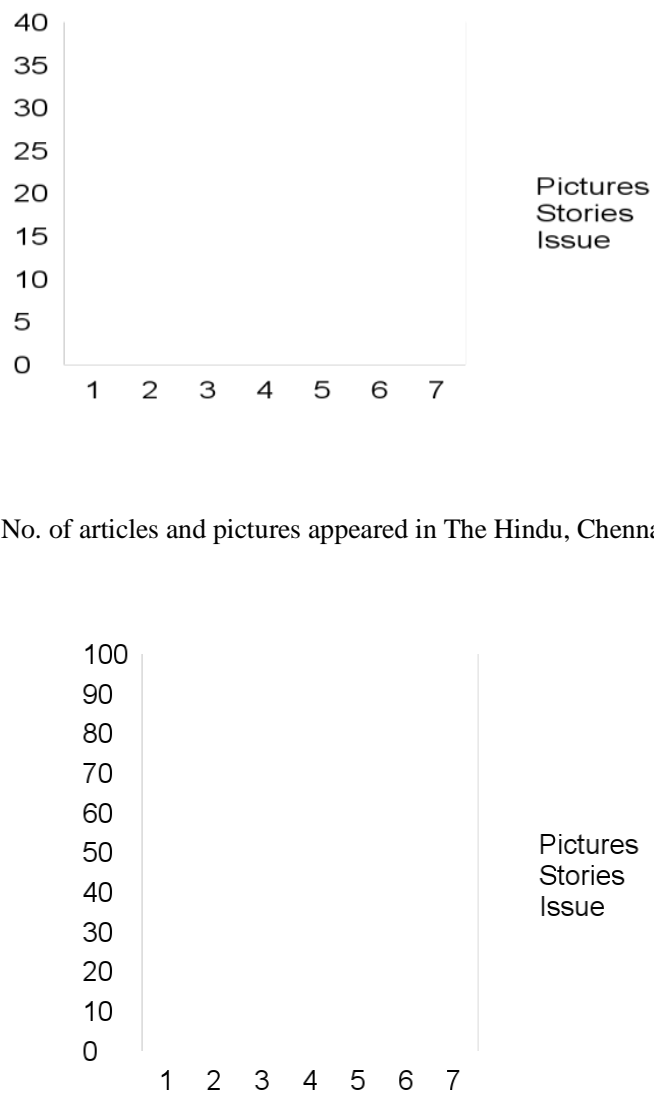

Graph 2 No. of articles and pictures that appeared in Dinathanthi,

\subsection{Number of stories in The Hindu}

During the time frame considered for the research, i.e., 13 January 2017 to 20 January 2017, 12 stories and 23 pictures were carried on the final day, 20 January 2017, followed by second highest of eight stories, 13 photos on 19 January 2017. The first five issues from 13 January to 18 January, in total there were 13 stories, 19 Pictures were carried.

\subsection{Number of stories in Dinathanthi}

During the time frame considered for this research, 37 cover stories, and 54 pictures were carried on 20 January followed by 34 stories and 42 photos on a day before, i.e., 19 January 2017. Interestingly, there were 13 stories and 15 pictures carried on 14 January 2017. 
There were at least more than 13 photos carried after 14 January every day and this continued to increase in the subsequent days.

\subsection{Number of stories on cover page}

In total, there were 13 articles regarding Jallikattu that appeared as front page articles in The Hindu and 20 items covering the same issue were covered extensively on the inside pages of the city section of the newspaper.

There were 26 articles regarding Jallikattu that appeared as front page articles in Dinathanthi and 20 articles which covered the same issue extensively were featured on the inside pages of the city section of the newspaper. A few of them even criticized several intellectuals and celebrities for their reactions and responses to the Jallikattu issue and for supporting the organization PETA.

Several opinion pieces were written by well-reputed personalities such as Vairamuthu, Pa.Vijay, Ameer, etc., This indicates the range and reach of the issue which created enough frenzy for an entire state to protest against the ban enforced on Jallikattu. As discussed by Mccombs and Shaw in their paper titled Agenda-setting and Mass media communication theory(1979) it may be understood that print media had a big part to play in garnering the support required to stage a massive protest against the ban imposed on Jallikattu by the Supreme Court.

\subsection{Placement of stories}

Table 3 Page prominence of content: Front Page Vs Inside page

\begin{tabular}{cccc}
\hline Page prominence & Front page & Inside page & Total \\
\hline The Hindu & 13 & 20 & 33 \\
Dinathanthi & 27 & 84 & 111 \\
\hline
\end{tabular}




\section{Front Vs Inside pages}

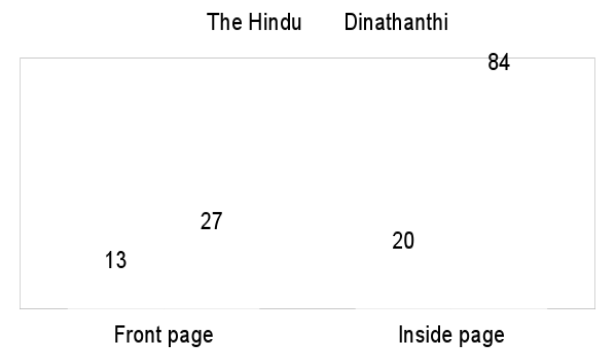

Graph 3: Page prominence of content: Front Page Vs Inside page

Table 4 Placement of content: Lead, Editorials and Opinions

\begin{tabular}{lccc}
\hline \multicolumn{1}{c}{ Particulars } & Lead & Editorials & Opinions \\
\hline The Hindu & 20 & 7 & 6 \\
Dinathanthi & 67 & 7 & 37 \\
\hline
\end{tabular}

\subsection{Place of content: Lead, Editorials and Opinions}

Upon further breaking down of the articles relating to the Jallikattu issue, the researchers were able to achieve a more profound understanding of the pattern of gradual increase in the number of pieces. 20 stories in The Hindu that were carried between the 13 January 2017 to 20 January 2017 were lead stories which indicated the importance of a cultural issue. While Dinathanthi carried 67 articles that were lead stories within the same timeframe. This comparison helps us understand that the importance given to a cultural question by the local newspaper is higher than that of the regular English daily.

The numerical evaluation indicates the agenda of the vernacular newspaper Dinathanthi which primarily focused on the local issue at stake and made the most of the trending situation. Whereas, The Hindu depicted a neutral stance and a gradual increase in coverage with accordance to the growing intensity of the issue which eventually led to a massive strike at Marina beach on the 20th of January, 2017. 
Placement of images: Page prominence of pictures

Table 5 Page prominence of pictures

\begin{tabular}{lccc}
\hline Page prominence & Front page & Inside page & Total \\
\hline The Hindu & 16 & 33 & 55 \\
Dinathanthi & 32 & 138 & 165 \\
\hline
\end{tabular}

\section{Picture: Front Vs Inside}

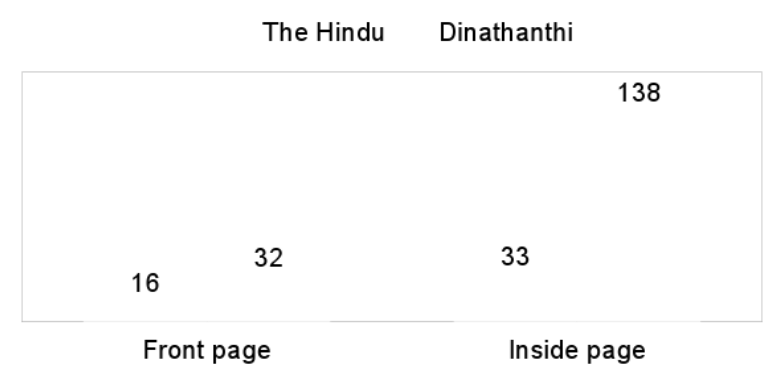

Graph 4 Page prominence of pictures

Types of images used

Table 6 Types of images

\begin{tabular}{lcccc}
\hline Particulars & The Happening & The epitome & People & Total \\
\hline The Hindu & 22 & 15 & 18 & 55 \\
Dinathanthi & 73 & 41 & 51 & 165 \\
\hline
\end{tabular}

The researcher had categorized the visual (picture) based content analysis into three different forms namely: The Happening, The Epitome and People. In the content analysis, researchers discovered that the majority of the pictures regarding the Jallikattu issue were classed as 'the happening' pictures and these were strategically placed as front page pictures.

Sixteen pictures regarding Jallikattu appeared as front page pictures in The Hindu and thirty three photos which appeared on 
the same issue were covered extensively in the inside pages of the city section of the newspaper.

Whereas in the case of Dinathanthi, 32 pictures regarding Jallikattu appeared as front page pictures and 138 pictures which discussed the same issue were covered extensively in the inside pages of the city section of the newspaper. Few of the photographs were of several intellectuals and celebrities along with their reactions and responses to the Jallikattu issue and support for the PETA organization. Several 'people' pictures utilized were of wellreputed personalities and actors such as Vijay, Suriya, Vikram, Trisha, Simbhu and many others. This represented the involvement of an entire state in protesting against the ban enforced on Jallikattu. The 'people' pictures that were published with relevance to this issue helped in bringing together masses from different sections of society with mutual opinion leaders in the form of intellectuals or celebrities.

Upon further analysis of the pictures published relating to the Jallikattu issue, the researchers were able to obtain a detailed understanding behind the gradual increase in the number of images. 22 photos in The Hindu that were published between the 13th January 2017 to 20th January 2017 were 'The Happening' pictures which showed the importance of a cultural issue whereas Dinathanthi carried 73 pictures that were 'The Happening' pictures between the same timeframe. This comparison helps us understand that the importance given to the issue by the local newspaper is greater than the English daily. The numerical evaluation shows the agenda of the vernacular newspaper Dinathanthi which primarily attempted make the issue most prominent news in the state. On the other hand, The Hindu showed a gradual increase but not escalation on the dramatic scale of the vernacular counterpart.

\section{Findings and Conclusion}

There were 27 articles (out of a total of 111 articles), 32 pictures (out of a total of 165 pictures) regarding Jallikattu that appeared as front page news in Dinathanthi in 7 issues. A few of them even criticized several intellectuals and celebrities for their reactions and responses for supporting PETA organization or animal rights. 
It has to be noted that the issue which is already in public debate was given priority by including opinion pieces from celebrities, mostly from the Tamil film industry. This was done to involve a larger number of readers in the issue, through opinion leaders.

Out of 165 pictures, 73 of those pictures in Dinathanthi were of 'Happening' nature which had an element of action, mostly contemporary, newsworthy and timely, and 22 'Happening' pictures were published by The Hindu.

In the growing fear about the decline of vernacular newspapers, it is a conscious decision taken by the papers to increase their readership in the race of economic survival. Dinathanthi's attempt seems close to achieving this goal by aligning itself with the desires of the masses. Although it is not objective to state whether media influenced people to gather at Marina beach on 20 January, 2017, one can't negate the contribution of media towards mass mobilization.

Both the newspapers framed the central government's role towards the entire issue in a negative manner. 13 photographs in The Hindu and 42 photographs in Dinathanthi were published one day before (19 January) the actual outburst that exploded at Marina beach on 20 January 2017. The pictures published by both newspapers were framed with the intention of attaining the attention of the readers and triggering a sense of rebellion. The frames displayed in the news can affect individuals and their public knowledge about the news topic. Framing has a large influence on society and individuals tend to mirror the viewpoint of the media, whether or not they are aware of it.

The newspaper coverage did have an impact on the ban on Jallikattu being removed. The decision resulted in people protesting for the continuation of the traditional art form. A high level of print media involvement through the selected newspapers is evident and the vernacular paper had more chauvinistic approach than the English daily. Every article or news story that pointed to the Jallikattu issue or related issues such as boycotting of PETA (animal welfare association) were covered extensively. A large influence of the selected newspapers may be observed while publishing of news articles regarding the Jallikattu issue. This helps in understanding 
the stand taken by the newspaper print media. The momentum gained by the Jallikattu issue can largely be credited to newspaper print media.

\section{Scope for Future Study and Limitations}

Although the paper had the potential scope of extending to other newspapers, only two newspapers have been considered. There is scope to further compare visual media and print media and their coverage pattern. Instead of comparing a national daily and a regional newspaper, several papers printed in the same language could also be investigated.

\section{References}

Gregorios, P. M. (1995). Speaking of tolerance and intolerance. India International Centre Quarterly.

Nussbaum, M. (2004). Religious Intolerance. Foreign Policy.

Macnamara, J. (2005). Media content analysis: Its uses, benefits and Best Practice Methodology. Asia Pacific Public Relations Journal, 6(1), 1- 34.

Marcus, G. E., Neuman, W. R., MacKuen, M. (2000). Affective Intelligence and Political Judgment. Chicago: University of Chicago Press.

McCombs, M., Bell, T. (1997) The agenda-setting role of mass communication. An integrated approach to communication theory and research. Mahwah, NJ: Lawrence Erlbaum Associates.

Robinson, J. P. (1976). Interpersonal Influence in Election Campaigns: Two step flow hypothesis. The public opinion quarterly.

Schefele D.A. and Tewsbury, D. (2007). Framing, Agenda Setting and Priming: The Evolution of Three Media Effects Models. Journal of Communication.

Shaw, E. (1979). Agenda Setting and Mass Communication Theory. International Communication.

Rashi, M. M. (2015). Agenda Setting, Religion and New Media. The Chabad case study JRMDC.

Gautier, F.(2001). A Western Journalist on India: The Ferengi's Columns, The Hindu. 